\title{
Short-term effects of regular salmeterol treatment on adult cystic fibrosis patients
}

\author{
J. Bargon, K. Viel, N. Dauletbaev, R. Wiewrodt, R. Buhl
}

\begin{abstract}
Short-term effects of regular salmeterol treatment on adult cystic fibrosis patients. J. Bargon, K. Viel, N. Dauletbaev, R. Wiewrodt, R. Buhl. (C)ERS Journals Ltd 1997. ABSTRACT: Cystic fibrosis $(\mathrm{CF})$ is characterized by chronic lung inflammation leading to airways obstruction. Bronchodilators, particularly short-acting $\beta_{2}$-agonists, are, therefore, often used by CF patients. The aim of this study was to evaluate, prospectively, the effects of the long-acting $\beta_{2}$-agonist salmeterol in adult $\mathbf{C F}$ patients.

Twenty six patients with CF (10 males and 16 females; mean age ( \pm SEM) $28 \pm 2$ yrs) with mild-to-moderate airways obstruction (baseline forced expiratory volume in one second/forced vital capacity (FEV1/FVC) $56 \pm 2 \%$ ) were monitored in an open, cross-over trial for 4 weeks by means of peak expiratory flow rates (PEFR), self-recorded symptom scores and body plethysmography. During a 2 week run-in period, all patients continued their treatment, including regular shortacting $\beta_{2}$-agonists. In weeks 3 and 4 , short-acting $\beta_{2}$-agonists were replaced by the long-acting $\beta_{2}$-agonist, salmeterol $(50 \mu \mathrm{g}$ b.i.d.).

Salmeterol produced a significant increase in PEFR compared to the run-in period (morning $375 \pm 23$ vs $332 \pm 23 \mathrm{~L} \cdot \mathrm{min}^{-1}, \triangle \mathrm{PEFR}+15.1 \pm 3.1 \%, \mathrm{p}<0.003$; evening $384 \pm 24$ vs $\left.349 \pm 24 \mathrm{~L} \cdot \mathrm{min}^{-1}, \triangle \mathrm{PEFR}+11.7 \pm 2.4 \%, \mathrm{p}<0.04\right)$. Similarly, patients reported lower symptom scores, $e . g$. less dyspnoea during the day, fewer nocturnal awakenings, less intense cough, and fewer unscheduled puffs of short-acting $\beta_{2}$-agonists.

Thus, the long-acting $\beta_{2}$-agonist salmeterol provided clinical benefit to a majority of adult cystic fibrosis patients with airways obstruction. These short-term results are promising enough to set up long-term controlled studies.
\end{abstract}

Eur Respir J 1997; 10: 2307-2311.

Division of Pulmonary Medicine, Dept of Internal Medicine II, Frankfurt University Hospital, Frankfurt/Main, Germany.

Correspondence: J. Bargon

Division of Pulmonary Medicine

Dept of Internal Medicine II

Frankfurt University Hospital

Theodor-Stern-Kai 7

D-60590 Frankfurt/Main

Germany

Keywords: Airways obstruction cystic fibrosis

long-acting $\beta_{2}$-agonists

short-acting $\beta_{2}$-agonists

Received: December 161996

Accepted after revision June 221997

ND was supported by Deutscher Akademischer Austauschdienst.
Lung disease in patients with cystic fibrosis $(\mathrm{CF})$ is characterized by an inflammatory process centred on the airways, with spreading to the submucosa [1-3]. Epithelial changes are early and include: denudation; impaired mucociliary clearance due to loss of cilia; squamous metaplasia; hypertrophy of mucous glands; and, later, mucopurulent plugging of the airways with acute and chronic inflammatory exudates leading to airways obstruction [4-7]. In addition to chest physiotherapy, bronchodilators, particularly short-acting $\beta_{2}$-agonists, are routinely prescribed by physicians and well accepted by a great majority of CF patients for relief of bronchoconstriction and to improve expectoration of bronchial secretions [8-11]. This is true despite the fact that the results of several studies focusing on the effect of bronchodilators in CF patients are contradictory $[4,7-9,11-$ 14].

Compared to the 4-6 h effect duration of short-acting $\beta_{2}$-agonists, inhaled long-acting $\beta_{2}$-agonists are characterized by a prolonged bronchodilator action for more

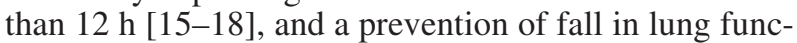
tion after allergen challenge for more than $30 \mathrm{~h}$ [19]. Current recommendations for the treatment of chronic bronchial asthma include the use of inhaled long-acting $\beta_{2}$-agonists when asthma symptoms are not controlled by a combination of inhaled corticosteroids and shortacting bronchodilators [20-24]. In chronic obstructive pulmonary disease (COPD), inhaled long-acting $\beta_{2}$-agonists may produce some symptomatic benefit even in patients with limited reversibility of airways obstruction [25-27]. Surprisingly, however, very little information is available regarding the effects of these drugs on pulmonary function or respiratory symptoms in patients with $\mathrm{CF}$ associated obstructive lung disease, especially given the widespread use of short-acting $\beta_{2}$-agonists in the disease management of these patients.

Thus, the aim of this study was to evaluate, prospectively, the effects of regular therapy with the long-acting $\beta_{2}$-agonist, salmeterol, on airways obstruction in $\mathrm{CF}$ patients. Salmeterol was chosen because it was the only inhaled long-acting drug available in Germany when the trial was started.

\section{Methods}

\section{Subjects}

Twenty six nonsmoking adult CF patients with obstructive airways disease enrolled at our $\mathrm{CF}$ out-patient clinic participated in this open, prospective, nonrandomized, crossover study (10 males and 16 females; mean age ( \pm SEM) $28 \pm 2$ yrs, range 21-58 yrs). In all patients, the diagnosis was confirmed by repeatedly positive sweat tests. Patients were asked to participate if pulmonary 
function tests documented an obstructive pattern (forced expiratory volume in one second (FEV1)/forced vital capacity (FVC) $\leq 80 \%$ ). All patients used short-acting $\beta_{2}$-agonists (salbutamol) regularly either as metered-dose inhalers (MDIs) or by inhalation with a nebulizer (Pari Master or Pari Boy; Pari, Starnberg, Germany) twice daily for at least $1 \mathrm{yr}$. All patients were well trained in using their MDI or nebulizer, and instructions were repeated once a year by a physiotherapist to avoid suboptimal treatment. In addition, most patients also used a short acting $\beta_{2}$-agonist via MDI as on-demand medication. The severity of CF lung disease was evaluated on the basis of the latest chest radiograph using the Chrispin-Norman score (pretherapy $12 \pm 0.7$, range 520 ) and pulmonary function tests (table 1). All patients attended the clinic regularly and showed no signs of acute infection during the study period.

\section{Study design}

During the first 2 weeks (days 1-14) of the 4 week study period, patients continued their regular medication without any change. Starting on day 15 , for the following 2 weeks, therapy with regular short-acting $\beta_{2}$-agonists was replaced by salmeterol, $50 \mu \mathrm{g}$ given unblinded twice daily via an MDI. Patients were asked to use short-acting $\beta_{2}$-agonists for symptom relief only. All subjects gave informed consent for the study. The study protocol was approved by the Institutional Review Board of Frankfurt University Hospital.

\section{Pulmonary function tests}

Pulmonary function tests were performed in a wholebody plethysmograph (Jaeger, Wuerzburg, Germany) before and $15 \mathrm{~min}$ after inhalation of $200 \mu \mathrm{g}$ salbutamol (two puffs) at the beginning (day 1) and at the end of the study (day 28). All tests were carried out between 10.00 and $12.00 \mathrm{~h}$, meeting the guidelines of the European Respiratory Society [28]. The best of three consecutive recordings was used in the analysis. Measurements included FVC, FEV1, peak expiratory flow (PEF), and airway resistance (Raw). Patients were instructed not to use short-acting bronchodilators for $6 \mathrm{~h}$ and long-acting $\beta_{2}$-agonists for $12 \mathrm{~h}$ prior to pulmonary function tests.

\section{Questionnaire and peak flow measurements}

Each patient received a peak flow meter with instructions on how to record in diary cards the best of three consecutive determinations of peak expiratory flow rates (PEFRs) before the first use of any bronchodilator in the morning (between 06.00 and $08.00 \mathrm{~h}$ ) and in the evening (between 19.00 and $21.00 \mathrm{~h}$ ) [29]. The patients also received a questionnaire for recording symptoms: shortness of breath $(0=$ none, $1 / 2=$ on heavy/light exertion, $3=$ at rest); coughing ( $0-3$ score points); sputum volume ( $\mathrm{mL}, 0-3$ score points); number of nocturnal awakenings due to breathlessness; and number of unscheduled puffs of short-acting $\beta_{2}$-agonist inhaled during the study period [30].

\section{Laboratory analysis}

At the beginning and at the end of the study, blood was drawn for laboratory analysis, testing; electrolytes, $\mathrm{C}$-reactive protein, erythrocyte sedimentation rate (ESR), renal function, and haematological parameters.

\section{Statistical analysis}

All data are presented as mean \pm SEM. Clinical and functional parameters during therapy with short-acting and long-acting $\beta_{2}$-agonists were compared using the Wilcoxon signed-rank test. A p-value equal to or less than 0.05 was considered significant.

\section{Results}

\section{Pulmonary function parameters}

All adult CF patients included in the study showed the typical features of obstructive airways disease (table $1)$. On day 1 , following two puffs of salbutamol (100 $\mu \mathrm{g} \cdot$ puff $\left.^{-1}\right), \mathrm{FVC}(+5.7 \pm 1.2 \%), \mathrm{FEV}_{1}(+7.0 \pm 1.2 \%), \mathrm{FEV}_{1} /$ FVC $(+0.75 \pm 0.73 \%)$, and PEF $(+6.6 \pm 3.4 \%)$ did not change significantly ( $>0.4$, all comparisons). Raw decreased by $25.2 \pm 2.4 \%(\mathrm{p}<0.03)$. Specifically, six patients responded to salbutamol with a change of FEV1 of $\geq 10 \%(14.5 \pm 1.5 \% ; \mathrm{p}<0.01)$, whilst in 9 and 11 patients changes were $5-10 \%(8.6 \pm 0.4 \% ; \mathrm{p}=0.01)$ and $\leq 5 \%$ $(1.6 \pm 0.5 \% ; p>0.5)$ of baseline, respectively. The addition of salmeterol to the patients' medication did not produce a significant change in FVC, FEV1, PEF or $R$ aw on day 28 ( $>>0.3$, all comparisons) (table 1). Similarly, the effect of salbutamol on pulmonary function parameters on day 28 was unchanged compared to day 1 ( $\mathrm{p}>0.2$, all comparisons).

\section{Peak expiratory flow rates}

During the 2 weeks of salmeterol treatment, mean morning and evening PEFRs increased significantly compared to the standard treatment period (mean morning PEFR $375 \pm 23$ vs $332 \pm 23 \mathrm{~L} \cdot \mathrm{min}^{-1}, \Delta \mathrm{PEFR}+15.1 \pm 3.1 \%$, $\mathrm{p}<0.003$; mean evening PEFR 384 \pm 24 vs $349 \pm 24 \mathrm{~L} \cdot \mathrm{min}^{-1}$, $\triangle \mathrm{PEFR}+11.7 \pm 2.4 \%, \mathrm{p}<0.04$ ) (figs. 1 and 2 ). In this regard, the degree of reversibility of airways obstruction by salbutamol predicted the therapeutic response to salmeterol. Patients with an initial FEV1 response to salbutamol of $\geq 10 \%$ showed significant PEFR increases due to salmeterol both in the morning and in the evening $(\mathrm{p}<0.02$, all comparisons); whilst in patients with an initial FEV1 response to salbutamol of $<5 \%$, PEFR did not differ significantly from the initial values $(\mathrm{p}>0.07)$.

\section{Symptomatic parameters}

The improvements in PEFRs with salmeterol were associated with significant improvements of symptomatic parameters. The degree of dyspnoea $(0.57 \pm 0.17 \mathrm{vs}$ $0.99 \pm 0.26 ; p<0.002$ ) (fig. 2) and the intensity of cough were lower $(1.84 \pm 0.17$ vs $2.25 \pm 0.19 ; \mathrm{p}<0.03)$. Salmeterol 
Table 1. - Results of pulmonary function tests of 26 cystic fibrosis (CF) patients before and after a 2 week period of treatment with salmeterol, $50 \mu \mathrm{g}$ b.i.d.

\begin{tabular}{|c|c|c|c|c|}
\hline \multirow[b]{2}{*}{ Parameter } & \multicolumn{2}{|c|}{ Before salmeterol treatment } & \multicolumn{2}{|c|}{ After salmeterol treatment } \\
\hline & Baseline & $\begin{array}{l}\text { Response to } \\
\text { salbutamol }\end{array}$ & Baseline & $\begin{array}{l}\text { Response to } \\
\text { salbutamol }\end{array}$ \\
\hline $\mathrm{FEV}_{1} \mathrm{~L}$ & $1.6 \pm 0.1$ & $1.7 \pm 0.1$ & $1.6 \pm 0.1$ & $1.7 \pm 0.1$ \\
\hline FEV1 $\%$ pred & $45 \pm 4$ & $48 \pm 4$ & $46 \pm 4$ & $48 \pm 4$ \\
\hline FVC L & $2.9 \pm 0.2$ & $3.0 \pm 0.2$ & $2.9 \pm 0.2$ & $3.0 \pm 0.2$ \\
\hline FVC \% pred & $67 \pm 4$ & $71 \pm 4$ & $69 \pm 4$ & $71 \pm 4$ \\
\hline $\mathrm{FEV} 1 / \mathrm{FVC} \%$ & $56 \pm 2$ & $57 \pm 2$ & $54 \pm 3$ & $55 \pm 2$ \\
\hline PEF $\quad \mathrm{L} \cdot \mathrm{s}^{-1}$ & $5.4 \pm 0.43$ & $5.7 \pm 0.44$ & $5.7 \pm 0.4$ & $5.9 \pm 0.4$ \\
\hline PEF \% pred & $64 \pm 4$ & $72 \pm 4$ & $70 \pm 4$ & $72 \pm 4$ \\
\hline Raw $\mathrm{cmH}_{2} \mathrm{O} \cdot \mathrm{L}^{-1} \cdot \mathrm{s}$ & $5.5 \pm 0.8$ & $4.0 \pm 0.6$ & $4.9 \pm 0.6$ & $4.0 \pm 0.5$ \\
\hline
\end{tabular}

Tests were always performed before (Baseline) and 15 min after inhalation of $200 \mu \mathrm{g}$ salbutamol. Data are presented as mean \pm SEM. FEV1: forced expiratory volume in one second; \% pred: percentage of predicted value; FVC: forced vital capacity; PEF: peak expiratory flow; Raw: airway resistance.

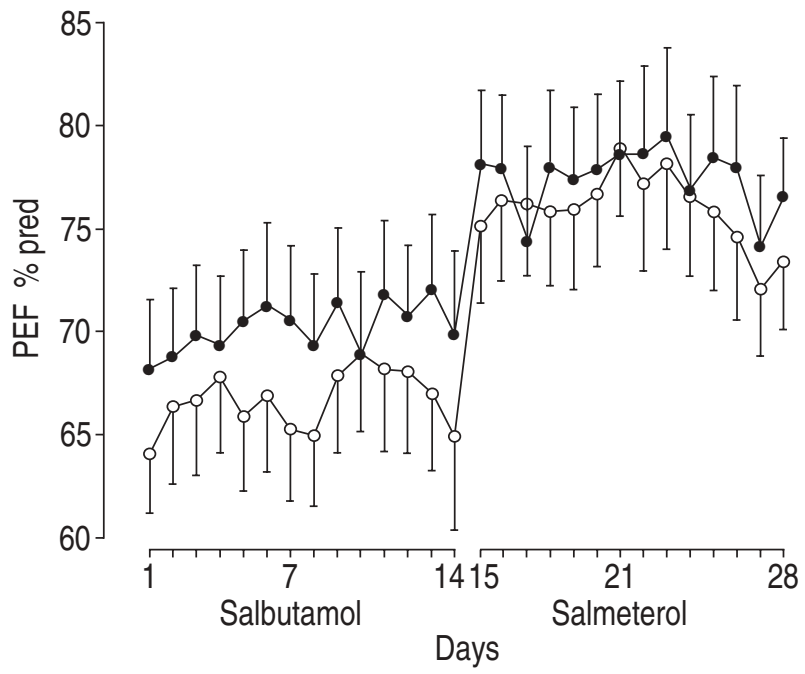

Fig. 1. - Mean morning and evening peak expiratory flow (PEF) rates as percentage of predicted value (\% pred) of 26 cystic fibrosis (CF) patients during 2 week periods of regular treatment with salbutamol and salmeterol. Values are presented as mean \pm SEM. ———: morning; ——- evening.

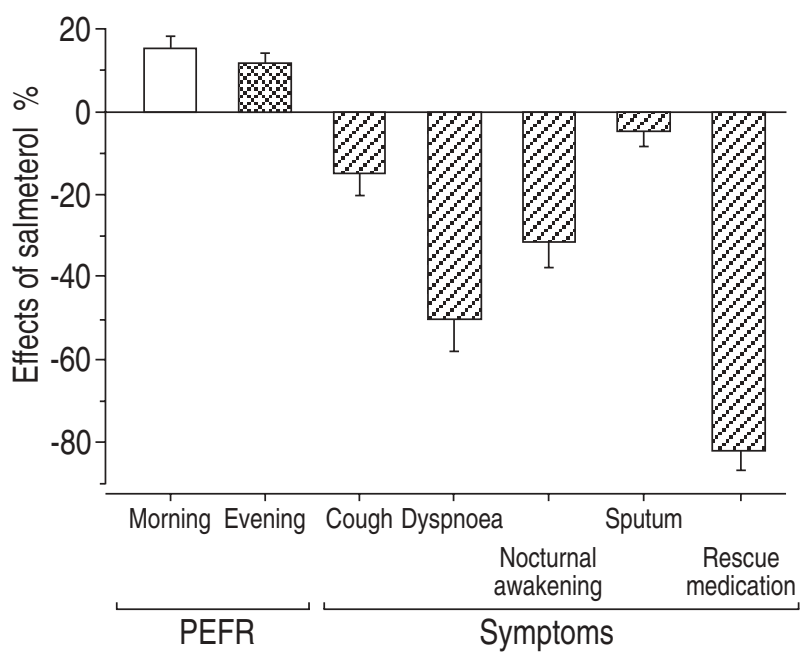

Fig. 2. - Effect of a 2 week period of treatment with salmeterol on peak expiratory flow rates (PEFRs) and symptoms of 26 cystic fibrosis $(\mathrm{CF})$ patients. The data are presented as the percentage change (mean \pm SEM) from baseline established during a 2 week period of regular therapy with salbutamol. also improved the quality of sleep (nocturnal awakenings per night $0.13 \pm 0.04 \mathrm{vs}$ $0.20 \pm 0.06 ; \mathrm{p}<0.015)$. This was paralleled by a decrease in the number of unscheduled puffs of short-acting $\beta_{2}$-agonists inhaled daily as on-demand medication $(0.07 \pm$ 0.04 vs $0.30 \pm 0.10 ; \mathrm{p}<0.001)$. Interestingly, dyspnoea improved even in the 11 patients who did not respond to salbutamol with a change of FEV1 of at least $5 \%(p<0.04)$. The symptomatic benefits were unrelated to changes in sputum production or clearance, the volume of expectorated sputum remained unchanged $(0.99 \pm 0.1$ vs $1.08 \pm$ $0.14 ; p>0.4)$. At the end of the salmeterol treatment period, 24 of $26 \mathrm{CF}$ patients asked for further therapy with long-acting $\beta_{2}$-agonists, the single most quoted motive being improved exercise capacity.

\section{Safety evaluation}

Three patients complained of tachycardia $(n=2)$, tremor $(n=1)$, and palpitations $(n=1)$ during the first study period. All these patients used more than two puffs of salbutamol daily in addition to their regular salbutamol dose $\left(2 \times 200 \mu \mathrm{g} \cdot \mathrm{day}^{-1}\right)$ when the symptoms occurred. One patient developed a pulmonary exacerbation during week two and had to be hospitalized. The results from this patient were not included in the study. In contrast, no adverse effects were noted during the study period attributable to the administration of salmeterol. Physical examination and all clinical and laboratory parameters remained stable during the salmeterol therapy period ( $p>0.5$, all parameters compared to standard therapy).

\section{Discussion}

Therapy of adult CF patients with airways obstruction with the long-acting $\beta_{2}$-agonist, salmeterol, significantly improved both morning and evening PEFRs and symptomatic parameters. The symptomatic benefit included some of the most frequent pulmonary complaints of adult $\mathrm{CF}$ patients, such as dyspnoea following exercise, and quality of sleep. Consequently, $92 \%$ of the patients included in this study asked for a continuation of therapy with long-acting $\beta_{2}$-agonists at the end of the study period.

Obstructive airways disease is frequently seen in a great majority of patients with $\mathrm{CF}$, and inhaled shortacting $\beta_{2}$-agonists are part of the standard therapy for this disease [7-11]. In a large multicentre trial evaluating the effects of aerosolized recombinant human deoxyribonuclease (rhDNase) on pulmonary function, more than $80 \%$ of participating CF patients were treated with bronchodilators [31]. However, there are conflicting reports on the effects of bronchodilating agents on pulmonary function in $\mathrm{CF}[10,11,13,14]$, including an increase in airway instability [12]. In a recent doubleblind, placebo-controlled study, inhaled salbutamol significantly improved pulmonary function in a majority of hospitalized CF patients [11]. Importantly, a decrease 
in pulmonary function overnight was observed, suggesting that longer-acting bronchodilators, such as longacting $\beta_{2}$-agonists or theophylline, may be helpful in $\mathrm{CF}$ patients. These findings support our hypothesis that long-acting $\beta_{2}$-agonists may improve control of $\mathrm{CF}$-associated airways obstruction and warrant further study.

In addition, several other factors suggest that this type of therapy could be beneficial for adult CF patients with airways obstruction. Firstly, long-acting $\beta_{2}$-agonists, such as salmeterol or formoterol, are effective bronchodilators with long duration, a clear advantage compared to short-acting $\beta_{2}$-agonists [15-19]. This is even more so in advanced airways obstruction, when symptom control by effective bronchodilators is necessary on a regular daily basis rather than on demand $[20,21]$. In such settings, addition of long-acting bronchodilators to the therapeutic regimen is clearly superior to increasing the dosage of conventional therapy [22-24]. Theoretically, treatment with short-acting $\beta_{2}$-agonists q.i.d. could have yielded similar subjective and objective results, at least during the day. However, a double-blind 3 month comparison of twice daily inhaled formoterol with inhaled salbutamol q.i.d. in patients with asthma demonstrated improved pulmonary function parameters both during the day and overnight, in the formoterol-treated patients [32]. Although the rationale for these recommendations was initially established in patients with bronchial asthma [16-18, 20-24], the results of the present study support the conclusion that long-acting $\beta_{2}$-agonists may be of similar value in $\mathrm{CF}$ patients with airways obstruction. In this regard, a great majority of adult CF patients regularly use $\beta_{2}$-agonists at least twice daily, and a major complaint of these patients is shortness of breath between inhalations. Thus, many patients have to make frequent use of short-acting $\beta_{2}$-agonists in addition to their regular twice daily schedule.

The observed lack of increase in FEV 1 contrasts with the increase in PEFR. This is surprising, since there is generally a good correlation between FEV1 and PEFR. This discrepancy is most likely due to the fact that PEFR measurements were performed in the early morning in the patient's home, whilst pulmonary function tests were carried out between 10.00 and $12.00 \mathrm{~h}$ in the hospital. The CF clinic in Frankfurt is a major referral centre for patients with $\mathrm{CF}$, and the limited physical mobility together with the dependency on public transportation of a great majority of patients made it impossible to schedule early hospital tests.

Secondly, as expected, the PEFR response of CF patients to salmeterol was largely dependent on the reversibility of airways obstruction. However, an unexpected result of this study was the fact that some form of clinical benefit due to salmeterol was seen in $93 \%$ of patients, rather independent of the degree of reversibility of airways obstruction. In this regard, the prolonged activation of $\beta_{2}$-adrenoceptors in $C F$ airways may not only provide prolonged bronchodilatation, but also lasting stimulation of ciliary function, another potential benefit in CF patients [33]. There is some similarity to the situation in patients with COPD. In COPD, salmeterol produced symptomatic relief and an improvement in quality of life, but only marginal effects on pulmonary function [25-27]. In the present study, a great majority of CF patients asked for further therapy with long-acting $\beta_{2}$-agonists, mostly due to improved exercise capacity. These results provide further evidence that bronchodilation is not the only mode of action of long-acting $\beta_{2}$-agonists.

Thirdly, the incidence of adverse effects reported to be attributable to salmeterol was surprisingly low, even given the small number of patients. In patients with asthma, side-effects of salmeterol and salbutamol are comparable in quality and quantity [34]. However, $\mathrm{CF}$ patients are familiar with this type of drug and the potential side-effects since early childhood, and may, therefore, be more likely to accept typical adverse effects as "normal".

Finally, the extent of obstructive airways disease in adults with $\mathrm{CF}$ is a key parameter of overall quality of life. Typical variables of quality of life in these patients, such as energy, pain, emotion, sleep, social isolation and physical mobility, show a highly significant correlation to measures of airways obstruction, such as FEV1 [35]. This strong correlation is notable because it is often not seen in other conditions, such as chronic bronchitis and emphysema.

A major concern regarding the chronic, regular use of $\beta_{2}$-agonists in patients with bronchial asthma is the potential development of tolerance against their effects, particularly on unspecific bronchial hyperresponsiveness, and even the induction of airway inflammation [36-39]. The 2 week treatment period in this study was too short to address these questions. From a theoretical point of view, it is unclear whether these considerations are valid in $\mathrm{CF}$, given the pronounced differences between the chronic neutrophil-dominated inflammatory process in the CF lung [1-3] and the chronic eosinophilic airways inflammation seen in bronchial asthma [20,21]. Nevertheless, bronchodilator therapy may impair lung function of CF patients [10-14]. It is, therefore, mandatory to monitor the effects both of short-acting and long-acting $\beta_{2}$-agonists on pulmonary function of each individual patient carefully, to recognize any such effects early, and to discontinue therapy if necessary. This is true despite the fact that salmeterol significantly decreased the number of puffs of short-acting $\beta_{2}$-agonists used as on-demand medication.

Long-acting $\beta_{2}$-agonists are not licensed for use in cystic fibrosis patients, and there are no documented clinical experiences with these drugs in this disease. Therefore, this open, nonrandomized, crossover study represents only a first step in the evaluation of long-acting $\beta_{2}$-agonists as a potential therapy for cystic fibrosisassociated obstructive lung disease. It showed, prospectively, the feasibility, efficacy, and safety of the use of long-acting $\beta_{2}$-agonists $(50 \mu \mathrm{g}$ salmeterol inhaled twice daily) in controlling bronchoconstriction and improving pulmonary symptoms when compared with the standard therapy with short-acting $\beta_{2}$-agonists. However, the message of this study is limited by its design, in particular the lack of blindness, potentially leading to placebo effects. Despite this, the results of this study demonstrate that long-acting $\beta_{2}$-agonists may be a valuable addition to the therapy of cystic fibrosis patients with obstructive lung disease, and that this type of drug is promising enough to justify long-term controlled studies in patients with cystic fibrosis. 
Acknowledgements: The authors thank CASCAN, Wiesbaden, Germany for providing the salmeterol used in this study.

\section{References}

1. Boat TF, Welsh MJ, Beaudet AL. Cystic fibrosis. In: Scriver CR, Beaudet AI, Sly WS, Valle D, eds. The Metabolic Basis of Inherited Disease. New York, McGrawHill, 1989; pp. 2649-2680.

2. Konstan MW, Hilliard KA, Norvell TM, Berger M. Bronchoalveolar lavage findings in cystic fibrosis patients with stable, clinically mild lung disease suggest ongoing infection and inflammation. Am J Respir Crit Care Med 1994; 150: 448-454.

3. Hodson ME. Respiratory system: adults. In: Hodson ME, Geddes DM, eds. Cystic Fibrosis. London, Chapman \& Hall, 1995; pp. 237-257.

4. Ormerod LP, Thomson RA, Anderson CM, Stableforth DE. Reversible airway obstruction in cystic fibrosis. Thorax 1980; 35: 768-772.

5. Tobin MJ, Maguire O, Reen D, Tempany E, Fitzgerald MX. Atopy and bronchial reactivity in older patients with cystic fibrosis. Thorax 1980; 35: 807-813.

6. Thomashefski JF, Abramowsky CR. The pathology of cystic fibrosis. In: Davis PB, ed. Cystic Fibrosis. New York, Marcel Dekker, 1993; pp. 435-489.

7. Cropp GJ. Effectiveness of bronchodilators in cystic fibrosis. Am J Med 1996; 100: 19S-29S.

8. Hordvik NL, König P, Morris D, Kreutz C, Barbero GJ. A longitudinal study of bronchodilator responsiveness in cystic fibrosis. Am Rev Respir Dis 1985; 131: 889-893.

9. Eggleston PA, Rosenstein BJ, Stockhouse CM, Mellits $\mathrm{ED}$, Baumgardner RA. A controlled trial of long-term bronchodilator therapy in cystic fibrosis. Chest 1991; 99: 1088-1092.

10. König P, Gayer D, Barbero GJ, Shaffer J. Short-term and long-term effects of albuterol aerosol therapy in cystic fibrosis: a preliminary report. Pediatr Pulmonol 1995; 20: 205-214.

11. Hordvik NL, Sammut PH, Judy CG, Strizek SJ, Colombo JL. The effects of albuterol on the lung function of hospitalized patients with cystic fibrosis. Am J Respir Crit Care Med 1996; 154: 156-160.

12. Zach MS, Oberwaldner B, Forche G, Polgar G. Bronchodilators increase airway instability in cystic fibrosis. $A m$ Rev Respir Dis 1985; 131: 537-543.

13. Reaburn D. Bronchodilator therapy in cystic fibrosis: for better or worse. Med Hypotheses 1988; 26: 59-62.

14. Zinman R, Wohl MEB, Ingram RH. Nonhomogenous lung emptying in cystic fibrosis patients. Am Rev Respir Dis 1991; 143: 1257-1261.

15. Rabe KF, Jörres R, Nowak D, Behr N, Magnussen H. Comparison of the effects of salmeterol and formoterol on airway tone and responsiveness over 24 hours in bronchial asthma. Am Rev Respir Dis 1993; 147: 1436-1441.

16. Ullmann A, Hedner J, Svedmyr N. Inhaled salmeterol and salbutamol in asthmatic patients. Am Rev Respir Dis 1990; 142: 571-575.

17. Pearlman DS, Chervinsky P, LaForce C, et al. A comparison of salmeterol with albuterol in the treatment of mild-to-moderate asthma. N Engl J Med 1992; 327: $1420-1425$.

18. Pearlman DS, Liddle R. Controlling asthma symptoms: salmeterol compared with salbutamol in large-scale, multicentre studies. Eur Respir Rev 1994; 21: 301-305.

19. Twentyman OP, Finnerty JP, Harris A, Palmer J, Holgate ST. Protection against allergen-induced asthma by salmeterol. Lancet 1990; 336: 1338-1342.

20. British Thoracic Society. Guidelines on the management of asthma. Thorax 1993; 48 (Suppl. 2): S1-S24.

21. National Heart, Lung and Blood Institute. National
Institutes of Health. Global strategy for asthma management and prevention. NHLBI/WHO Workshop Report. NIH publication No. 95-3659. Bethesda, MD, US Department of Health and Human Services, 1995.

22. Greening AP, Ind PW, Northfield M, Shaw G. Added salmeterol versus higher-dose corticosteroid in asthma patients with symptoms on existing inhaled corticosteroid. Lancet 1994; 344: 219-224.

23. Woolcock A, Lundback B, Ringdal N, Jacques LA. Comparison of addition of salmeterol to inhaled steroids with doubling of the dose of inhaled steroids. Am J Respir Crit Care Med 1996; 153: 1481-1488.

24. Faurschou P, Steffensen I, Jacques L. Effect of addition of inhaled salmeterol to the treatment of moderate-tosevere asthmatics uncontrolled on high-dose inhaled steroids. Eur Respir J 1996; 9: 1885-1890.

25. Cazzola M, Matera MG, Santangelo G, Vinciguerra A, Rossi F, D'Amato G. Salmeterol and formoterol in partially reversible severe chronic obstructive pulmonary disease: a dose-response study. Respir Med 1995; 89: 357-362.

26. Grove A, Lipworth BJ, Reid P, et al. Effects of regular salmeterol on lung function and exercise capacity in patients with chronic obstructive airways disease. Thorax 1996; 51: 689-693.

27. Jones PW, Bosh TK, in association with an international study group. Quality of life changes in COPD patients treated with salmeterol. Am J Respir Crit Care Med 1997; 155: 1283-1289.

28. Quanjer PH, Tammeling GJ, Cotes JE, Pedersen OF, Peslin R, Yernault J. Lung volumes and forced ventilatory flows. Report Working Party Standardization of Lung Function Tests, European Coal and Steel Community. Official Statement of the European Respiratory Society. Eur Respir J 1993; 6 (Suppl. 16): 5-40.

29. Dekker FW, Schrier AC, Sterk PJ, Dijkman JH. Validity of peak expiratory flow measurement in assessing reversibility of airflow obstruction. Thorax 1992; 47: 162-166.

30. Brooks SM, Ayer H, Discher DP, et al. Surveillance for respiratory hazards in the occupational setting. Am Rev Respir Dis 1982; 127: 952-956.

31. Fuchs HJ, Borowitz DS, Christiansen DH, et al. Effect of aerosolized recombinant human DNAse in exacerbations of respiratory symptoms and on pulmonary function in patients with cystic fibrosis. $N$ Engl $\mathrm{J}$ Med 1994; 331: 637-642.

32. Kesten S, Chapman KR, Broder I, et al. A three month comparison of twice daily inhaled formoterol versus four times daily inhaled albuterol in the management of stable asthma. Am Rev Respir Dis 1991; 144: 622-625.

33. Wood RE, Wanner A, Hirsch J, Farrell PM. Tracheal mucociliary transport in patients with cystic fibrosis and its stimulation by terbutaline. Am Rev Respir Dis 1975; 111: 733-738.

34. Fuller R. Safety of salmeterol in the treatment of asthma. Eur Respir Rev 1995; 27: 133-137.

35. Congleton J, Hodson ME, Duncan-Skingle F. Quality of life in adults with cystic fibrosis. Thorax 1996; 51 : 936-940.

36. Sears MR, Taylor DR, Print CG, et al. Regular inhaled beta-agonist treatment in bronchial asthma. Lancet 1990; 336: 1391-1396.

37. Inman MD, O'Byrne PM. The effect of regular inhaled albuterol on exercise-induced bronchoconstriction. Am J Respir Crit Care Med 1996; 153: 65-69.

38. Drazen JM, Israel E, Boushey HA, et al. Comparison of regularly scheduled with as-needed use of albuterol in mild asthma. $N$ Engl J Med 1996; 335: 841-847.

39. Cockroft DW, Swystun VA. Functional antagonism: tolerance produced by inhaled $\beta_{2}$-agonists. Thorax 1996; 51: 1051-1056. 